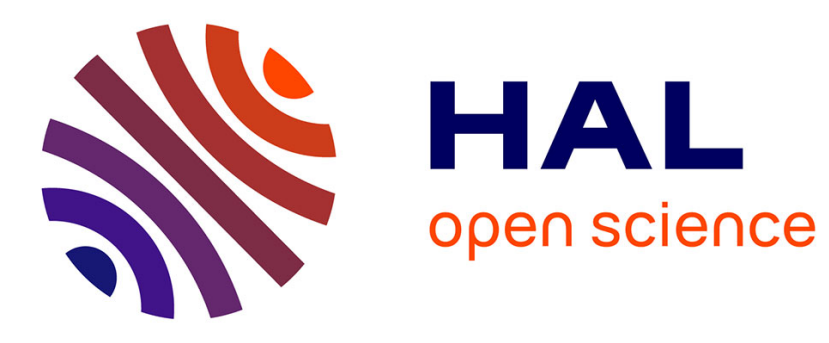

\title{
Extrusion Criterion for Firm Cement-based Materials
}

Arnaud Perrot, Damien Rangeard, Yannick Mélinge, Patrice Estellé,

Christophe Lanos

\section{To cite this version:}

Arnaud Perrot, Damien Rangeard, Yannick Mélinge, Patrice Estellé, Christophe Lanos. Extrusion Criterion for Firm Cement-based Materials. Applied Rheology, 2009, 19 (5), pp.53042. 10.3933/ApplRheol-19-53042 . hal-00664473

HAL Id: hal-00664473

https://hal.science/hal-00664473

Submitted on 24 Sep 2012

HAL is a multi-disciplinary open access archive for the deposit and dissemination of scientific research documents, whether they are published or not. The documents may come from teaching and research institutions in France or abroad, or from public or private research centers.
L'archive ouverte pluridisciplinaire HAL, est destinée au dépôt et à la diffusion de documents scientifiques de niveau recherche, publiés ou non, émanant des établissements d'enseignement et de recherche français ou étrangers, des laboratoires publics ou privés. 


\title{
Extrusion criterion for firm cement-based materials
}

\author{
Arnaud Perrot ${ }^{a,{ }^{*}}$, Damien Rangeard ${ }^{b}$, Yannick Mélinge ${ }^{b}$, Patrice Estellé ${ }^{b}$, Christophe Lanos ${ }^{b}$ \\ ${ }^{a}$ UEB- LIMAT B, Université de Bretagne Sud, Centre de Recherche de St Maudé, 56321 LORIENT, \\ France

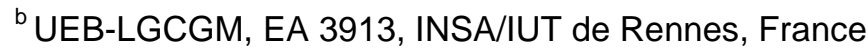 \\ * Corresponding author \\ Email: arnaud.perrot@univ-ubs.fr \\ Tel : +33 (0) 297874577 \\ Fax : +33 (0) 297874572
}

\begin{abstract}
:
The stability of the flow induced by the extrusion forming process of a cement based material is largely influenced by the relative migration between the lubricating liquid phase and the granular skeleton. In the present work, we propose linking rheological concepts and soil mechanics (consolidation theory, Darcy's law) to reach a simple criterion which predicts the extrusion ability of a mortar. Extrusion tests on studied mortar are performed at different ram velocities for criterion validation.
\end{abstract}

\section{Résumé :}

La stabilité de l'écoulement du procédé de mise en forme par extrusion de matériaux à base cimentaire est largement influencée par la migration relative entre la phase liquide et le squelette granulaire. Dans ce travail, nous proposons de lier les concepts de rhéologie et de mécanique des sols (théorie de la consolidation, loi de Darcy) pour définir un critère simple qui prédit l'aptitude à l'extrusion d'un mortier. Des essais d'extrusion à différentes vitesses de piston sont ensuite réalisés pour valider le critère.

\section{Zusammenfassung :}

Die Stabilität des durch Ausstoßungsformen-Prozeß eines Zements veranlassten Flusses stützte Material ist in hohem Maße unter Einfluß der Verhältnismigration zwischen Schmieren der flüssigen Phase und granulierten Skelettes. In der gegenwärtigen Arbeit haben wir vor, rheology und Boden-Mechanik-Begriffe (Verdichtungstheorie, Gesetz von Darcy) zu verbinden, um ein einfaches Kriterium zu reichen(erreichen), das die Ausstoßungsfähigkeit des Mörsers(Mörtels) voraussagt. Ausstoßungstests auf an verschiedenem Widder durchgeführten Zementteigen.

\section{Keywords:}

Drainage, Extrusion, Filtration, Mortar 


\section{Introduction}

Extrusion is a common forming process for a wide range of materials (food, polymer, clay, metal). For perfect and homogeneous plastic materials, the extrusion stress and the flow typology have been well described, as they are the subject of numerous studies [1-3]. For cement-based materials, extrusion could be a high productivity forming process which is expected to improve the mechanical properties of the formed material (limiting the water content and voids ratio in comparison with precast concretes) [4-6]. Mu et al. [4], Peled and Shah [5] or Zhou et al. [6] showed that the extrusion process is able to form hardened cement composites with higher mechanical properties than the traditional casting process. Those studies focused on cementbased pastes with admixtures, such as viscosity agents or plasticizers, reinforced with different types of fibres. Such engineered cement composites present optimized mechanical properties. But, the cost is very high and the forming of such a paste is often penalized by excessive fluidity of the mix. Cement-based materials behave as visco-plastic materials which are commonly modelled by a Bingham law as proposed by Roussel [7], De Larrard et al. [8] or Wallevick [9]. Such mixes are characterized by a value of yield stress higher than $1 \mathrm{kPa}$. For the extrusion of such materials, yield stress has to be high enough for the material to retain its shape when leaving the extruder as proposed by Toutou et al. $[10,11]$. The common usable yield stress value is evaluated at $20 \mathrm{kPa}$.

Consequently, there is not yet a common industrial-scale way to form coarse cement-based materials with an acceptable rate of admixture. As mentioned by Roussel et al. [12] and Toutou et al. [10] this can be both explained by the heterogeneity (large range of grain sizes) and the specific rheological behaviour (frictional behaviour due to high solid volume fraction) of such materials.

In extrusion flow, these properties give such concentrated materials a granular-like behaviour which induces a liquid phase filtration through the granular skeleton as shown by Perrot et al., $[13,14]$. Consequently, the extrusion flow is largely influenced by induced heterogeneities which can lead to process blockage. The flow-induced heterogeneities in the extruder may also affect the quality of the extrudates, thus impeding such a process in an industrial setting. In this case, the flow is governed by the concurrency between the velocity of the fluid filtration and the velocity of the process $[11,13]$. This phenomenon has also been observed for clay paste by Götz et al. [15-16] and Yu et al. [17]. The fluid filtration is governed by the consolidation equations and has been applied to clay paste extrusion by Burbidge et al. [18]. They have used the consolidation theory of Terzaghi to model the fluid filtration through the granular skeleton for clay extrusion. However, according to these authors, this theory seems to be limited by the evolution of granular skeleton permeability during extrusion which is not taken into account in the classical equations of Terzaghi [19]. More recently, Martin et al. [20] have used the Wroth and Housby for non-axisymetric extrusion of clay criterion to predict if the extrusion flow would remain undrained. Modified cam-clay modelling has been used by Patel et al. [21] to compute the evolution of extrudate water content during extrusion. However, not one gives indications of the impact of paste consolidation on its rheology. Soils mechanics has been also used to study the fresh behaviour and the setting of cement-based materials $[22,23]$.

The aim of the study is to go a step further by defining a criterion based on the soil mechanics approach for extrusion velocity to avoid flow induced heterogeneities. Flow induced heterogeneities have to be integrated on macroscopic parameters, such as yield stress and material permeability. Such material mixture variation directly affects the extrusion load and material rheology. This impact on the flow properties has to be predicted to be able to design extrudible materials. 
In a first step, the material mixture and its rheology are studied. The material mixture is based on the previous work of Toutou et al. [10,11]. The influences that mortar age and liquid content have on paste yield stress are shown. Then, the hydro-mechanical properties of the mortar are investigated using the soils mechanic approach (consolidation theory). The granular skeleton permeability and the liquid filtration kinetics through static granular skeletons are studied.

An analytical computation is then performed during flow and gives the evolution of the yield stress of material undergoing ram extrusion. Finally, an extrudability criterion is defined and its efficiency is shown through experimental tests carried out on the studied mortar.

\section{Materials}

\subsection{Mix design}

The mortar used in this study fills all the extrudability criteria defined by Toutou et al. [10-11]. The material is firm enough to retain its shape under gravity and handling. Tests were carried out on a mortar with a water/cement weight ratio of 0.25 . A water reducing admixture (Sika plastiment 22S) is added to the water in the following weight ratio: Plasticizer/Cement $=0.01$. The binder used is a mix of 70 weight percent of Portland cement 32.5 CEM IIB with 20 percent of finely crushed $(15 \mu \mathrm{m}$ maximum particle diameter) volcanic rock (pozzolane), 5 percent of silica fume $(0.1 \mu \mathrm{m}$ maximum particle diameter) and 5 percent of amorphous crushed quartz $(10 \mu \mathrm{m}$ maximum particle diameter). The addition of filler fines gives better homogeneity and plastic performance to the paste. Mortars were obtained adding fine sand (maximal diameter of grains: $0.630 \mathrm{~mm}$ ) in a weight ratio Sand/Cement $=0.8$. The final fresh mortar presents a high yield stress (about $20 \mathrm{kPa}$ ) and a high solid volume fraction $(76.8 \%)$.

The protocol of mixing is detailed by Perrot et al. [13] and extrusion tests are performed 20 minutes after the end of mixing to avoid aging effects.

\subsection{Rheological behaviour}

The yield stress of the studied material is measured with vane tests. A four-bladed probe of 8 $\mathrm{mm}$ in radius $R_{\mathrm{i}}$ and height $\mathrm{H}$ is used for the measurements. Tests performed at different rotational speeds ( 0.1 to $10 \mathrm{rpm})$ give the same recorded torque-displacement curves (Figure 1). Consequently, it is assumed that shear stress does not depend on shear rate: the mortar behaviour is mainly plastic. Moreover, the viscous behaviour component of the paste is negligible in the extrusion flow of cement-based materials as shear rate remains low. We presently consider that when the flow is initiated the yield stress $\mathrm{K}$ is reached on the sheared surface (Estelle et al. [24]; Nguyen and Boger [25]). Using a $20 \mathrm{~cm}$ diameter cup avoiding wall slip effects, we finally obtain eq. 1:

$$
K=\frac{M}{2 \pi \cdot H \cdot R_{i}^{2}}(1)
$$

Where $\mathrm{M}$ is the maximal torque recorded during shearing.

Vane test results show that the mortar exhibits a nearly perfect plastic behaviour which is independent of the shear rate. However, yield stress evolves linearly with time due to thixotropic and setting effects [7] (Fig. 1). To prevent those time dependent effects, extrusion tests are performed at the same paste age (20 minutes after mixing). 
Mortars are concentrated suspensions. For such materials, some authors have linked the yield stress to the material solid volume fraction (Flatt, [26]; Legrand [27]; Chateau [28]; Ildefonce et al. [29]). Due to liquid filtration during extrusion, the material solid volume fraction is expected to evolve in the extruder. As a result, the material yield stress will be affected. To evaluate the yield stress/solid volume fraction dependency, the yield stress of 7 different water content mixtures is measured.

When using the soil mechanics theory, the evolution of yield stress should be expressed in function of the void ratio e. Void ratio is related to the solid volume fraction $\phi$ using the following relationship:

$$
e=\frac{1-\phi}{\phi}(2)
$$

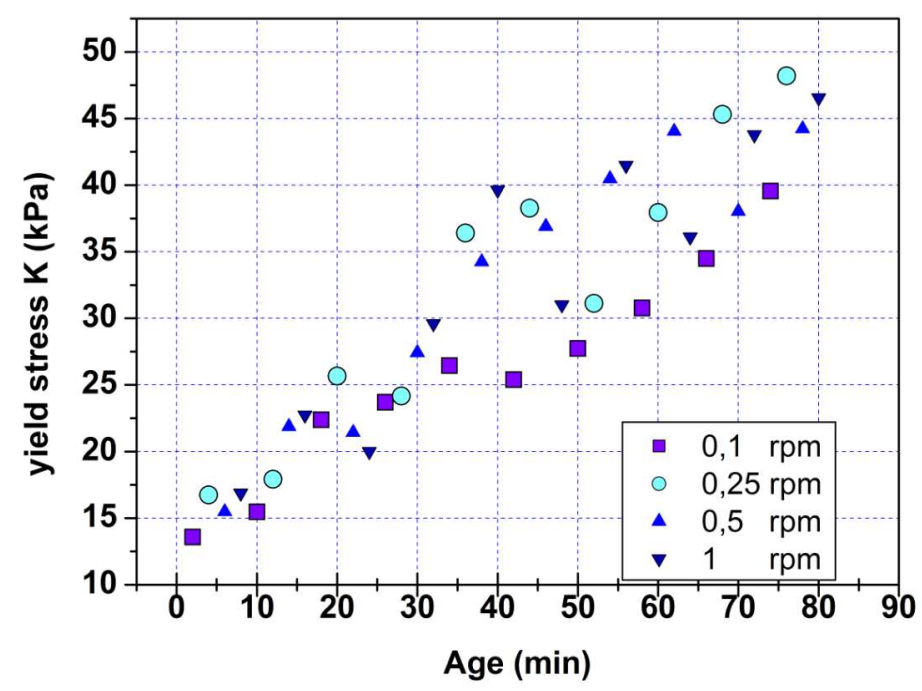

FIGURE 1. Mortar yield stress evolution in function of time. Paste void ratio e $=0.29$

The Legrand model is used to link the yield stress to the void ratio. In terms of void ratio, the Legrand model is written as:

$$
K=a \cdot \exp \left(0.5 b \frac{1-e}{1+e}\right)
$$

with $\mathrm{a}$ and $\mathrm{b}$ fitting parameters.

Other quoted models can be used [26-29]. The Legrand model has been used in this case for its simplicity. However, Fig. 2 shows that it has also correctly predicted the evolution of the material yield stress against void ratio.

\subsection{Hydro-mechanical behaviour analysis}

The hydro-mechanical behaviour of the mortar is investigated using a one dimensional compression test (oedometer test). The apparatus used in this study was adapted to cement-based materials. The tested samples are $42 \mathrm{~mm}$ in height and $30 \mathrm{~mm}$ in diameter. A drained condition 
is imposed on the top of the sample by a filter grid system, whereas the bottom is kept undrained during all the tests.

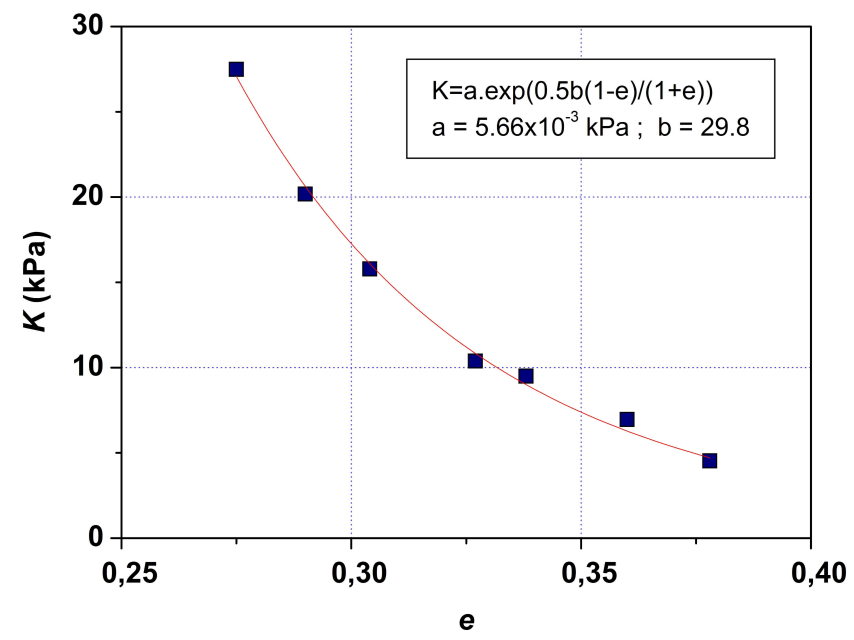

FIGURE 2. Experimental mortar yield stress evolution in function of solid volume fraction. Comparison with Legrand modelling. Age of the paste at the beginning of each measurement: 20 minutes.

First, a series of creep tests (constant load tests) were performed at different stress levels varying from $100 \mathrm{kPa}$ to $400 \mathrm{kPa}$. For all of these tests, the load is kept constant for 60 minutes. Then, a compressibility test is performed from a step-by-step increase of the applied stress (classical oedometer test procedure for soils).

Fig. 3 shows the decrease of the sample height with the time obtained from the different creep tests. This figure shows that the mortar behaves as common clay. At the beginning of the test, settlement increases with time before getting a final value independent of the time. The first evolution is characteristic of primary consolidation (i.e. fluid filtration through granular skeleton). At the end of the primary consolidation, a linear settlement evolution with time characterises the secondary consolidation (viscous behaviour). In the case of the studied mortar, the settlement does not vary after the primary consolidation, which means that the viscous behaviour is negligible when compared to consolidation behaviour.

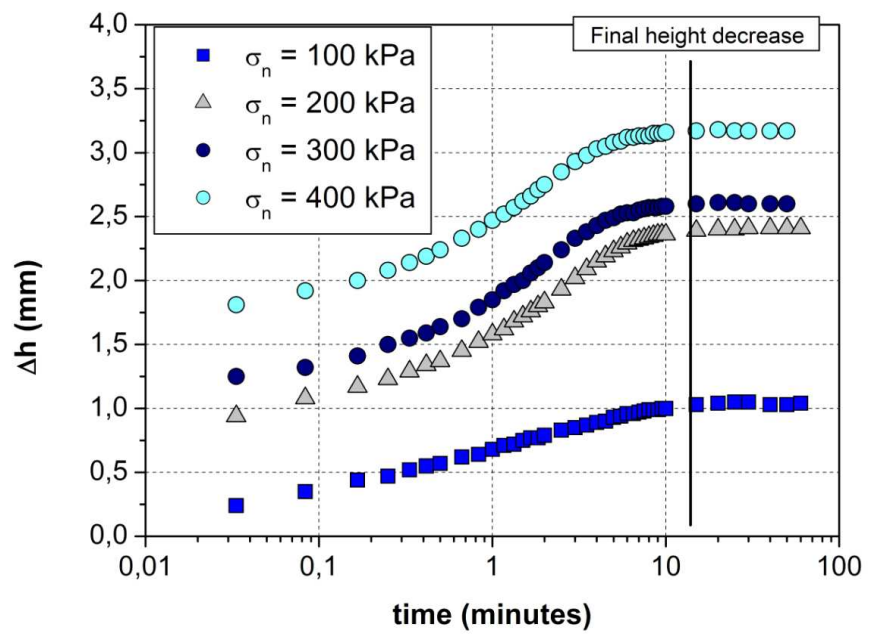

FIGURE 3. Results of the oedometer tests on the mortar: constant loading tests - consolidation kinetics study. Age of the paste at the beginning of test: 15 minutes. 
The amount of time needed to reach the stabilized value of the settlement, characterising the end of primary consolidation, seems to be almost constant for all the tests and is close to 15 minutes. During this period the effect of aging on the paste rheology is neglected as the variation of the yield stress remains lower than $15 \%$.

The settlement curves are analysed to determine the consolidation coefficient $c_{v}$ which describes the kinetics of liquid filtration. The values of $c_{v}$ obtained for each stress level are summarised in Tab. 1. It can be noted that the consolidation coefficient seems to be little influenced by the loading level.

After analysing creep tests, a complete compressibility test is performed by a step-by-step increase of the stress level. From the creep test results, each loading increment is set at 15 minutes, corresponding to the end the consolidation process. Seven stress levels are performed: the first four by increasing the stress level (loading), the last three by decreasing the stress level (unloading). This kind of test has enabled us to determine the amplitude of the settlement according to the stress load history. The evolution of the void ratio versus the logarithm of the stress level obtained from this test is plotted in Fig. 4.

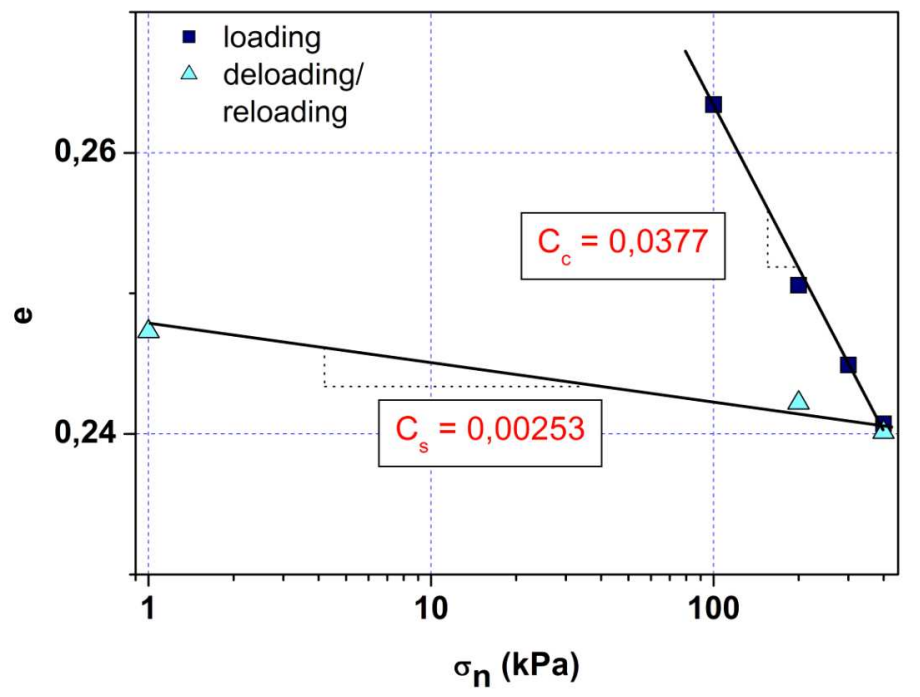

FIGURE 4. Results of the oedometer tests on the mortar: loading levels tests - consolidation amplitude study

From these results, the evolution of the void ratio with stress is described by two compressibility coefficients which convey the linear link between void ratio and stress level logarithm. The first one, $\mathrm{C}_{c}$, characterises primary loading (plastic compression behaviour), the second one, $\mathrm{C}_{\mathrm{s}}$, characterises the pseudo elastic reversible behaviour, obtained in this case by unloading. The obtained values of $\mathrm{C}_{\mathrm{c}}$ and $\mathrm{C}_{\mathrm{s}}$ are respectively 0.038 and 0.0025 . The mortar exhibits common soil type behaviour.

The permeability $\mathrm{k}$ of the mortar can be extrapolated from the consolidation coefficient using Eq. 4:

$$
k=\frac{c_{v}}{1+e_{0}} \frac{\Delta e}{\Delta \sigma_{n}} \gamma_{w}
$$

where $\mathrm{e}_{0}$ is the initial value of $\mathrm{e}, \Delta \mathrm{e}$ is the variation of e related to a variation of the normal stress $\Delta \sigma_{\mathrm{n}}$ and $\gamma_{\mathrm{w}}$ the unit weight of water. 
The values of the permeability, determined for the different void ratio, are summarised in Tab. 1.

\begin{tabular}{|c|c|c|c|c|}
\hline$\sigma_{\mathrm{n}}(\mathrm{kPa})$ & 100 & 200 & 300 & 400 \\
\hline $\mathbf{c}_{\mathbf{v}}\left(\mathrm{m}^{2} / \mathrm{s}\right)$ & $5.79 \times 10^{-6}$ & $4.96 \times 10^{-6}$ & $5.64 \times 10^{-6}$ & $5.60 \times 10^{-6}$ \\
\hline Average $\mathrm{c}_{\mathrm{v}}\left(\mathrm{m}^{2} / \mathrm{s}\right)$ & & $5.46 \times 10^{-3}$ & $4.51 \times 10^{-3}$ & $3.33 \times 10^{-3}$ \\
\hline$\Delta \mathbf{e} /\left(\mathbf{1}+\mathbf{e}_{0}\right)$ & & $3.16 \times 10^{-9}$ & $2.24 \times 10^{-9}$ & $1.89 \times 10^{-9}$ \\
\hline $\mathbf{k}(\mathrm{m} / \mathrm{s})$ & & 0.290 & 0.273 & 0.261 \\
\hline e (average e during stress step) & & \multicolumn{4}{|c|}{5.2013} & \\
\hline
\end{tabular}

TABLE 1. Summary of the compressibility test results on studied mortar. Results obtained during the step-by-step increase of stress level.

The permeability evolution with void ratio is not negligible. To model this evolution, Eq. 5, which was first proposed by Taylor [30], is presently used. As shown in Fig. 5, this leads to a value $c_{\mathrm{k}}$ of 0.12 (Table 2 ).

$$
\Delta\left[\log _{10} k\right]=\frac{\Delta e}{c_{k}}(5)
$$

\begin{tabular}{|c|c|c|c|c|}
\hline \multicolumn{2}{|c|}{$\mathbf{e}_{0}(\mathbf{k P a})$} & 0.29 & 0.273 & 0.261 \\
\hline \multirow{3}{*}{$\mathbf{k}(\mathbf{m} / \mathbf{s})$} & oedometer values & $3.16 \times 10^{-9}$ & $2.24 \times 10^{-9}$ & $1.89 \times 10^{-9}$ \\
\cline { 2 - 5 } & permeameters value & $3.20 \times 10^{-9}$ & & \\
\cline { 2 - 5 } & Taylor modelling $\left(C_{k}=0.125\right)$ & $3.09 \times 10^{-9}$ & $2.30 \times 10^{-9}$ & $1.85 \times 10^{-9}$ \\
\hline
\end{tabular}

TABLE 2. Comparison of experimental permeability value in function of void ratio with Taylor modelling

The permeability of the mortar is also measured at a constant void ratio e $=0.29$ by a constant load permeameter. The hydraulic load is $1.2 \mathrm{~m}$ and the sample height is $10 \mathrm{~mm}$ and the diameter is $50 \mathrm{~mm} .5 \mathrm{ml}$ flows for 79 minutes. As a result, the computed permeability with Darcy's law is $3.1 .10^{-9} \mathrm{~m} \cdot \mathrm{s}^{-1}$. This value is in correlation with the ones obtained through oedometer testing (Table 2).

\section{Material evolution in the extruder}

\subsection{Modelling}

The modelling process focuses on an elementary layer located at the top of the extruder close to the ram. In this area, the liquid phase flows down toward the die as the ram is waterproof. As a result the studied layer is mainly submitted to a normal compressive stress with a filtration flow through the bottom surface as in a one-surface drained oedometer. A homogeneity criterion must be fund regarding the following question: does the liquid phase of the studied layer have the time to flow through the granular skeleton before the material leaves the extruder?

To solve the problem, filtration equation (Darcy's law) is used:

$$
V_{f i l t}=\frac{k(e)}{\rho_{w} g} \cdot \frac{\Delta P}{\Delta x}(6)
$$

Where $\rho$ is the interstitial fluid density, $\mathrm{V}_{\text {filt }}$ is the fluid filtration velocity and $\Delta \mathrm{P} / \Delta \mathrm{x}$ is the axial stress gradient in the extruder. The pressure gradient used was found from the stress balance equation applied on an elementary layer of thickness $\Delta \mathrm{x}[14]$. 


$$
\frac{\Delta P}{\Delta x}=\frac{4 \cdot K(e)}{D}(7)
$$

where $\mathrm{D}$ is the extruder diameter and $\mathrm{K}$ the shear yield stress. By coupling Eqs (6) and (7) we obtain the time required to decrease the paste void ratio of a variation $\Delta \mathrm{e}$ :

$$
\Delta t=\frac{\rho_{w} g}{k(e)} \cdot \frac{\Delta e}{1+e_{0}} \cdot \frac{D}{4 \cdot K(e)} \cdot \Delta x
$$

with $\mathrm{e}_{0}$ the initial void ratio.

The time required to decrease the void ratio of a given value for a height sample is computed and added to obtain the void ratio evolution. We note here that the oedometer theory is limited to low a height sample to assume the material is homogeneous (same $\mathrm{K}$, e and $\mathrm{k}$ inside the sample).

Between two computation steps, the material void ratio evolves. As a result, the yield stress $\mathrm{K}$ of the mortar and the permeability $\mathrm{k}$ of the granular skeleton vary. Thus, at each step, values of $\mathrm{K}$ and $\mathrm{k}$ are changed according to Eqs 3 and 5 respectively.

In a first approach, the permeability is assumed to be constant and equal to $3.2 .10^{-9} \mathrm{~m} \cdot \mathrm{s}^{-1}$. This approach is similar to the one used by Burbidge et al. [18]. As the permeability does not vary a lot, this assumption seems rational. In this case, the problem formulation is mathematically written as:

$$
\left\{\begin{array}{l}
\Delta t=\frac{\rho_{W} g}{k} \cdot \frac{\Delta e}{1+e_{0}} \cdot \frac{D}{4 \cdot K(e)} \cdot h_{0} \\
K(e)=a \cdot \exp \left(0.5 b \frac{1-e}{1+e}\right)
\end{array}\right.
$$

where $\mathrm{h}_{0}=\Delta \mathrm{x}$, the initial sample height.

To take into account, the influence of the permeability evolution, we include in the previous formulation the evolution of permeability in function of void ratio. Eq. 9 finally becomes:

$$
\left\{\begin{array}{l}
\Delta t=\frac{\rho_{W} g}{k(e)} \cdot \frac{\Delta e}{1+e_{0}} \cdot \frac{D}{4 \cdot K(e)} \cdot h_{0} \\
K(e)=a \cdot \exp \left(0.5 b \frac{1-e}{1+e}\right) \\
\Delta\left[\log _{10} k(e)\right]=\frac{\Delta e}{c_{k}}
\end{array}\right.
$$

Eqs (9) and (10) are expected to correctly predict the evolution of yield stress during extrusion.

\subsection{Experimental device and tests}

An axisymetrical ram extruder is used for tests. $\operatorname{Ram}(\mathrm{D}=43.3 \mathrm{~mm})$ and die $(\mathrm{d}=15 \mathrm{~mm})$ present a circular cross section. For the present study, the die consists in an abrupt contraction (angle of the die entry equal to $90^{\circ}$ ). The sample mass is equal to $600 \mathrm{~g}$.

Tests are performed in the same geometry conditions as in reference [14]. In this work, authors highlight the evolution of material yield stress during extrusion. The author obtained a measurement grid of the local surface hardness of the paste. This measurement was shown to be proportional to the material yield stress. 
The idea of this test is to compare those experimental yield stress values taken from Perrot [14] with computed value obtained with the modelling presented in section 3.1. More precisely, we compare the evolution of the average yield stress in the $10 \mathrm{~mm}$-layer located at the ram to the computed yield stress. The experimental average yield stress is obtained by averaging the yield stress values located at a distance of $5 \mathrm{~mm}$ from the ram. This averaged value is assumed to be representative of the mortar of the layer which is assumed to be homogeneous in the modelling. The two modelling developed in section 3.1 by Eqs 9 and 10 are used in the given experimental conditions (i.e. with and without taking into account permeability evolution). A numerical convergence is obtained for a step of void ratio $\Delta \mathrm{e}$ of $10^{-4}$. For higher value of $\Delta \mathrm{e}$ (i.e. $10^{-3}$ ), the computation does not converge.

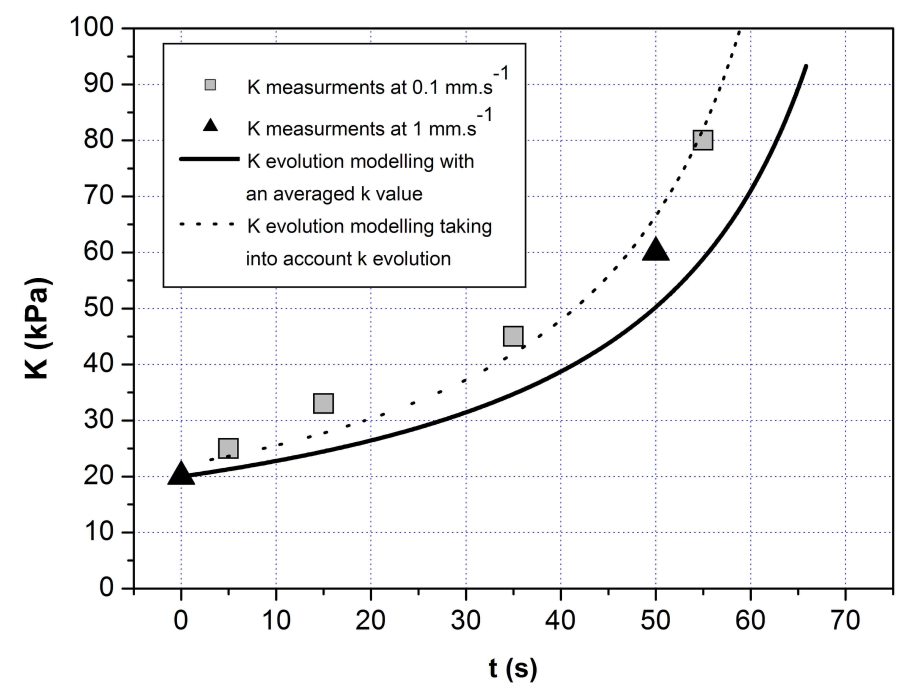

FIGURE 5. Extrusion behaviour: evolution of the yield stress of the mortar in the ram area during extrusion comparison between modelling and experiments

Fig. 5 shows that the most influencing parameter to describe the yield stress evolution is the time of extrusion. One can see that for the two studied velocities, the material yield stress vs. the extrusion time can be plotted on a same curve. This is in correlation with the assumptions used: the material is not viscous and the top of the extruder can be considered as an oedometer.

Experimental and analytical data are in quite good agreement with and without taking into account permeability evolution (Fig. 5). It means that the permeability evolution has only little influence on yield stress variation (20\% of difference at 40 seconds). However, this is not negligible and taking the permeability evolution into account allows for better correlation of experimental data.

To find a parameter reflecting the consolidation effect on rheological behaviour, we decided here to consider the time required to double the initial yield stress in the mortar $\left(t_{K(t)=2 . K(t=0)}\right)$. At rest, without any solicitations, this time is about 60 minutes, when regarding only aging effects (Fig. 1). During the extrusion process, the time $t_{K(t)=2 . K(t=0)}$ in the studied layer (near the ram) is equal to 30 seconds (Fig. 5).

The evolution of the yield stress during extrusion is mostly affected by the consolidation process due to fluid migration. The aging effects are negligible for the duration of this test.

\subsection{Proposed criterion}


The proposed criterion consists of computing the ratio of the duration of extrusion (material length over ram velocity $\mathrm{V}$ ) over the time needed to double the initial yield stress value (noted $\left.t_{K(t)=2 K(t=0)}\right)$. Such a value can be easily computed using the previous rheological and hydromechanical analysis.

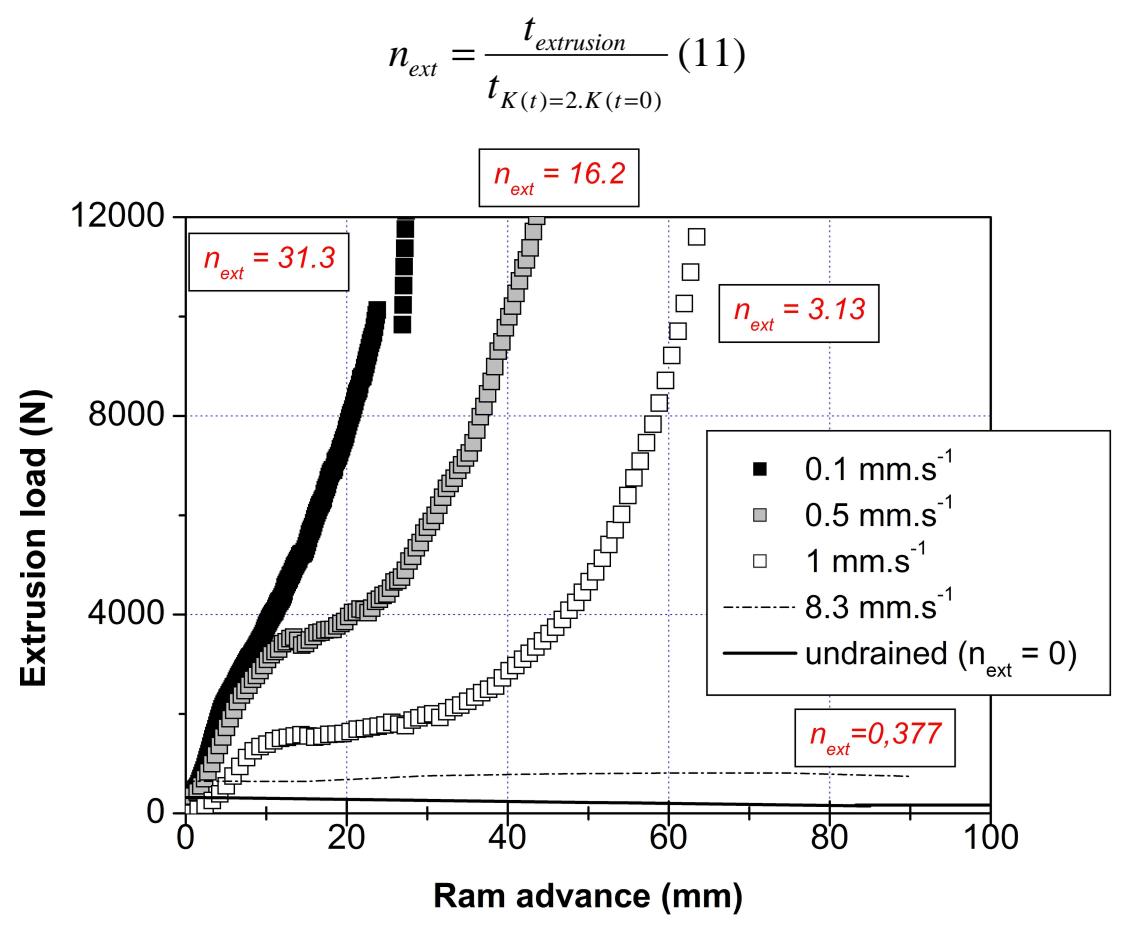

FIGURE 6. Extrusion behaviour: evolution of the yield stress of the mortar in the ram area during extrusion - comparison between modelling and experiments

If the criterion ratio $n_{\text {ext }}$ tends to 0 , the consolidation velocity is negligible compared to the extrusion velocity. As a result, the material remains homogeneous and extrusion continues. Inversely, if $\mathrm{n}_{\mathrm{ext}}$ increases, consolidation has enough time to affect material rheology and thus extrusion load (Fig. 6). In consequence, the smallest value of $n_{\text {ext }}$ has to be searched and used.

Such a value is a good index for the extrusion ability of the material as it directly conveys the ability of the material to remain homogeneous during extrusion. Note that the time required to finish the extrusion is not sufficient enough to explain the blockage only with the hardening phenomenon described in Fig. 2.

\section{Conclusions}

The proposed approach and modelling enable one to define a criterion identifying multiphase flow during mortar extrusion. The kinetics of rheological evolution (yield stress increase) is identified and a non-dimensional number is defined as the ratio of the time of extrusion over the time needed to double the yield stress of the material in the ram area. This number predicts if the material will remain homogeneous and if the extrusion load will increase.

The experimental data highlight the small effect of aging on the yield stress evolution of the mortar according to the yielding due to the consolidation effect.

\section{References}

[1] Benbow JJ, Bridwater J: Paste Flow and extrusion, Clarendon Press, Oxford (1993). 
[2] Hill R: Mathematical theory of plasticity, Clarendon Press, Oxford (1950).

[3] Zienkiewicz OC and Godbole PN: Flow of plastic and viscoplastic solids with a special reference to extrusion and forming process, International Journal of Numerical Methods In Engineering. 8 (1974) 3-16.

[4] Mu B, Li Z, Chui SNC and Peng J: Cementitious composite manufactured by extrusion technique, Cement and concrete research 29 (1999) 237-240.

[5] Peled A and Shah SP: Processing effects in cementitous composites: Extrusion and casting, Journal of Materials in Civil Engineering (2003) 192-199.

[6] Qian X, Zhou X, Mu B, Li Z: Fiber alignment and property direction dependency of FRC extrudates, Cement and Concrete Research 33 (2003) 1575-1581.

[7] Roussel N: Steady and transient flow behaviour of fresh cement pastes, Cement and Concrete Research 35 (2005) 1656-1664.

[8] De larrard F, Hu C, Sedran T, Szitkar JC, Joly M, Claux F and Dekx F: A new rheometer for soft to solid fresh concrete, ACI Materials Journal (1997) 234-243.

[9] Wallewik $\mathrm{OH}$ and Gjorv OE: Development of a coaxial viscometer for fresh concrete, Properties of fresh concrete, RILEM, Hanover (1990) 213-224.

[10] Roussel N, Lanos C and Mélinge Y: Induced heterogeneity in saturated flowing granular media, Powder Technology 138 (2003) 68-72.

[11] Toutou Z, Lanos C and Mélinge Y: The use of squeezing test-extrusion flow similitude to identify cement based materials extrudability, Proceedings of the XIVth International Congress On Rheology, Seoul, Korea (2004) MP23.

[12] Toutou Z, Roussel N and Lanos C: The squeezing test, a tool to identify firm cement based material's rheological behaviour and evaluate their extrusion ability, Cement and Concrete Research 35 (2005) 1891-1899.

[13] Perrot A, Lanos C, Estellé P and Mélinge Y: Ram extrusion force for a frictional plastic material: model prediction and application to cement paste, Rheologica Acta 45 (2006) 457-467.

[14] Perrot A, Lanos C, Estellé P and Mélinge Y: Mortar physical properties evolution in extrusion flow, Rheologica Acta 46 (2007) 1065-1073.

[15] Götz J, Buggish H, Peciar M: NMR imaging of pastes in a ram extruder, Journal of NonNewtonian Fluid Mechanics 49 (1993) 251-275.

[16] Götz J, Kreibich W and Peciar M: Extrusion with a piston extruder for the determination of the local solid and fluid concentration, the local porosity and saturation and displacements profiles by means of NMR imaging, Rheologica Acta 41 (2002) 134-143.

[17] Yu AB , Burbidge AS, Bridgwater J, Saracevic Z: Liquid maldistribution in particulate paste extrusion, Powder Technology 103 (1999) 103-109.uhouhyo^hy

York (1943).

[20] Martin PJ, Wilson DI, Bonnett PE, Paste extrusion through non-axisymmetric geometries: insights gained by application of a liquid phase drainage criterion, Powder Technology 168 (2006) 64-73.

[21] Patel MJ, Wedderburn J, Blackburn S, Wilson DI, Maldistribution of fluids in extrudates, Journal of the European Ceramic Society 29 (2009) 937-941. 
[22] Amziane S, Andriamanantsilavo N, Prediction of cement paste pore water pressure variations during setting period, Advances in Cement Research 16 (2004) 23-28.

[23] Amziane S, Setting time determination of cementitious materials based on measurements of the hydraulic pressure variations, Cements and Concrete Research 36 (2006) 295-304.

[24] Estelle P, Perrot A, Lanos C, Amziane S, Processing the vane shear flow data from Couette analogy. Appl. Rheol. 18 (2008) 34-37.

[25] Nguyen QD, Boger DV: Characterization of yield stress fluids with concentric cylinder viscometers, Rheol. Acta 26 (1987) 508-515.

[26] Flatt RJ: Towards a prediction of superplasticized concrete rheology. Materials and Structures 37 (2004) 289-300.

[27] Legrand C: La structure des suspensions de ciment, in Le Béton hydraulique, Ed. de l'ENPC, Paris (1982).

[28] Chateau X, Ovarlez G, Trung KL: Homogenization approach to the behavior ofsuspensions of noncolloidal particles in yield stress fluids, J. Rheol. 52 (2008) 489-506.

[29] Ildefonse B, Allain C, Coussot C : Des grands écoulements naturels à la dynamique du tas de sable. Cémagref édition, Paris (1997).

[30] Taylor DW: Fundamentals of Soil Mechanics, John Wiley and Sons, New York (1948).

\section{Figure Captions:}

FIGURE 2. Mortar yield stress evolution in function of time

FIGURE 2. Mortar yield stress evolution in function of solid volume fraction with Legrand modelling.

FIGURE 3. Results of the oedometer tests on the mortar: constant loading tests - consolidation kinetics study

FIGURE 4. Results of the oedometer tests on the mortar: loading level tests - consolidation amplitude study

FIGURE 5. Extrusion behaviour: evolution of the yield stress of the mortar in the ram area during extrusion - comparison between modelling and experiments

FIGURE 6. Extrusion behavior: evolution of the yield stress of the mortar in the ram area during extrusion - comparison between modeling and experiments

\section{Tables Caption :}

TABLE 1. Summarize of oedometer test results on studied mortar

TABLE 2. Comparison of experimental permeability value in function of void ratio with Taylor modelling 